\title{
The Hippocampus and Social Impairment in Psychiatric Disorders
}

\author{
Matthew Schafer and Daniela Schiller \\ Department of Psychiatry, Department of Neuroscience, and Friedman Brain Institute, \\ Icahn School of Medicine at Mount Sinai, New York, New York 10029, USA \\ Correspondence: daniela.schiller@mssm.edu
}

\begin{abstract}
Social deficits, such as poor social skills (i.e., the inability to engage in appropriate and effective social interactions) and social withdrawal, are prevalent across psychiatric disorders and often co-occur with hippocampal structural and functional abnormalities. The centrality of both social and hippocampal dysfunction in psychiatric research prompts the question: Are they linked? The social cognitive map framework provides a clue: The hippocampus tracks social information in the physical environment, maps others along social dimensions, and supports social memory and decision-making. Hippocampal dysfunction might disrupt social map representation and contribute to commonly seen social behavioral symptoms. This review summarizes evidence for the role of the hippocampus in social cognitive mapping, followed by evidence that hippocampal dysfunction and social dysfunction co-occur in psychiatric disorders. We argue that the co-occurrence of hippocampal and social impairment may be related via hippocampal social cognitive mapping.
\end{abstract}

Functions ascribed to the hippocampal formation, such as spatial representation and episodic memory, can be explained by a more general function: cognitive mapping (i.e., relational modeling; Tolman 1948; O'Keefe and Nadel 1978; Schiller et al. 2015). Map-like information is encoded by a wide variety of cell types in the hippocampal formation (i.e., dentate gyrus, hippocampal CA subfields, subicular complex, entorhinal cortex). In the spatial domain, pyramidal neurons in the hippocampal formation encode current location ("place cells"; O'Keefe and Nadel 1978) periodically fire to "tile" the environment ("grid cells"; Hafting et al. 2005) and give distance and direction information to landmarks (Deshmukh and Knierim 2013), boundaries (Solstad et al. 2008), objects (Høydal et al. 2018), and goals (Sarel et al. 2017) -all functions consistent with spatial mapping. The hippocampal formation also encodes head direction (Sargolini et al. 2006), speed (Kropff et al. 2015), and routes (Javadi et al. 2017), and individual cells can alter their firing properties on the basis of the current behavioral goal (Wood et al. 2000).

Episodic information is organized in a similar manner as physical space. The hippocampus encodes a "memory space" by binding elements of experience (Eichenbaum 2014). For example, the hippocampus encodes conjunctive information, such as the combination of particular places and items (Komorowski et al. 2009), tracks temporal context ("time cells"; MacDonald et al. 2011), and links events across time (Davachi and DuBrow 2015). This form of mapping extends beyond the spatial and episodic domains and reflects a general relational process: Sensory (Teki et al. 2012; Julian et al. 2018), abstract (reward; Gauthier and Tank 2018), and even conceptual (Quian
Quiroga et al. 2009; Constantinescu et al. 2016) information with similar statistical structure (e.g., the same number of dimensions) is encoded similarly by the hippocampal formation and often by the same cells that map the spatial environment.

The literature suggests an emerging view: The hippocampal formation extracts and organizes behaviorally relevant information about the current space (e.g., physical space, task space) into a relational format (Behrens et al. 2018; Bellmund et al. 2018; Schafer and Schiller 2018). In other words, the hippocampal formation models the underlying statistical regularities of experience, binding informational elements into maps of arbitrary scale (e.g., from specific to general) and abstraction (i.e., information not reducible to immediate sensory perception, such as reward)

Cell types in the hippocampal formation could be considered basis functions, whose flexible reweighting allows for a wide range of relational structures to be encoded and stored in a map-like format (Behrens et al. 2018). Map retrieval may occur via pattern completion, whereby partial, noisy inputs are "completed" into stored representations by spreading ensemble activation: The network of neurons activated at encoding reactivates and stabilizes upon partial activation due to intrahippocampal recurrent excitation (Gold and Kesner 2005; Okamoto and Ikegaya 2018). Maps should be encoded and stored in a nonoverlapping fashion, so as to not interfere with each other when retrieved (i.e., pattern separation; Yassa and Stark 2011) with hippocampal remapping possibly reducing interference between related representations (Colgin et al. 2008).

Generalizing from stored maps could constrain representations of the current space and generate predictions

(C) 2018 Schafer and Schiller. This article is distributed under the terms of the Creative Commons Attribution-NonCommercial License, which permits reuse and redistribution, except for commercial purposes, provided that the original author and source are credited. 
of future states (e.g., available trajectories and possible outcome values) through map-based simulations-crucially reducing the computational cost of predicting realworld outcomes where the possibilities are practically unlimited. Cognitive maps may be fundamentally predictive, with map elements representing predictions of future states that can be integrated with other predictions (e.g., reward) to compute values (Stachenfeld et al. 2017). Alternatively, maps may be used as inputs in decision-making processes (Miller et al. 2018) by providing the model for simulations and predictions about relationships between stimuli (Hindy et al. 2016), even stimuli that were never directly experienced together (i.e., inferences). For example, in familiar spaces, place cell sequences can reactivate to simulate spatial trajectories to rewards (Singer and Frank 2009), even for entirely novel trajectories (Ólafsdóttir et al. 2015).

In spaces with unfamiliar statistical structure, relational elements of stored maps are retrieved and reconfigured into novel sequences to represent possible maps and trajectories (Bellmund et al. 2018), perhaps guided by prediction error-related plasticity. Such reconfiguration may even allow the construction of entirely imagined episodes (Schacter et al. 2012). Ultimately, cognitive mapping is about goal pursuit: Relational models are a flexible substrate to predict information about current and future spaces and engage in goal-directed behavior to maximize reward and minimize threat (Behrens et al. 2018; Bellmund et al. 2018; Schafer and Schiller 2018).

\section{MAPPING SOCIAL SPACE}

Understanding social relationships, contexts, and dimensions (e.g., hierarchy), and inferring the likely mental states and actions of others, are all important for humans to successfully navigate ambiguous, often changing social environments to maximize social reward and minimize social threat. Social information varies continuously along dimensions, suggesting that, much like the hippocampus does for other domains, the hippocampus may organize social information into maps to guide social decisionmaking ("social navigation"; Tavares et al. 2015; Montagrin et al. 2018; Schafer and Schiller 2018). For example, social dimensions of power and affiliation impact social relationships in rodents (Insel and Fernald 2004), nonhuman primates (Brent et al. 2013), and humans (Todorov et al. 2008; Fiske 2012). The hippocampus is important in both dimensions, such as in representing and updating social hierarchies (Kumaran et al. 2012, 2016) and in affiliative behaviors (Machado and Bachevalier 2006).

The dimensions of power and affiliation are computed jointly by the hippocampus (along with other regions; e.g., dorsolateral prefrontal cortex, inferior parietal lobule, precuneus/posterior cingulate cortex) as a two-dimensional social coordinate space (Tavares et al. 2015). Specifically, in a role-playing game where participants interact with characters during functional magnetic resonance imaging (fMRI), hippocampal signal correlated with social interaction decisions along power and affiliation dimen- sions. Characters were plotted in this two-dimensional social space relative to the participants' point of view. As information from interactions accumulated, hippocampus activity correlated with vector angles from participant to characters in social space, tracking the relative power and affiliation of each character across time. In other words, the hippocampus tracked social trajectories. The magnitude of this hippocampal effect correlated with selfreported social skills, suggesting that social mapping is important to social behavior (Tavares et al. 2015). Indeed, hippocampal-dependent memory predicts social network size in healthy adults (Stiller and Dunbar 2007), whereas hippocampus damage impairs social memory (Sanders and Warrington 1971) and leads to smaller social networks (Davidson et al. 2012).

Maps represent relationships between elements, without explicitly encoding the elements themselves. For example, hippocampus activity relates to faces associated with biographical or behavioral information (Todorov et al. 2007) and faces that are famous or personally known (Trinkler et al. 2009), but not faces unassociated with other social information (Bird et al. 2007; Aly et al. 2010). Additionally, maps represent information abstracted away from sensory details, suggesting social cognitive maps about a specific individual could be activated by different sensory cue types (e.g., a person's name or a photo of their face). Indeed, hippocampal neurons that preferentially activate to familiar faces relative to other visual stimuli (Kreiman et al. 2000) can also respond invariantly to the same individual across sensory modalities (Quian Quiroga et al. 2009), suggesting they store a conceptual representation of specific individuals. The hippocampus appears therefore crucial to social memory that relates the conceptual representation of an individual to other stored social information (e.g., prior interactions, behavioral tendencies, etc.). For example, the hippocampus may stabilize character judgments by relating current behavior to past behavior (Croft et al. 2010).

As in other forms of mapping, social cognitive maps could allow the simulation and prediction of social information-such as what thoughts and behaviors someone is likely to engage in, and outcomes of social reward and threat. In addition to maps related to others, self-related hippocampal maps (e.g., representing one's own experiences, behavioral tendencies) could also be generalized to constrain the computational expense of social prediction and decision-making. Indeed, self-related hippocampal memory may inform inferences about others' mental states (i.e., mentalizing) during events, especially when an individual has perceived the other person as similar and has experienced a similar event (Perry et al. 2011).

Mapping could also extend to relationships in social contexts themselves: The hippocampus encodes information both within and across contexts (Davachi and DuBrow 2015), a function that could extend to the social domain to enable accurate predictions in diverse social situations. Normative social behavior is contextual; accurate action selection depends on organizing a broad range of social information - the current place (e.g., a sporting event vs. work), the persons involved (e.g., family vs. 
strangers), and their likely moods (e.g., disappointment after a team's loss vs. excitement after a win). Social cognitive mapping may provide the substrate to make these predictions and engage in subtle, situation appropriate social behavior.

\section{NEURAL MECHANISMS OF SOCIAL MAPPING}

Social mapping functions may encode information similarly to more basic forms of mapping (e.g., spatial). Hippocampal subregions dorsal CA2 (dCA2; posterior in humans) and ventral CA1 (vCA1; anterior in humans) are especially important to social recognition (Hitti and Siegelbaum 2014; Smith et al. 2016; Meira et al. 2018), and both subfields contain place cells that encode social information (Alexander et al. 2016; Danjo et al. 2018; Omer et al. 2018), suggesting place cell activity could partially underlie social recognition. CA2 and CA1 also have densely distributed oxytocin and vasopressin receptors, which are neuropeptides important in many social and bonding behaviors and are mediators in CA2's role in social recognition (Smith et al. 2016; Lin et al. 2017). Oxytocin in particular tunes CA2 to CA1 information processing: Oxytocin receptor binding enhances information transfer from CA2 to CA1 (Tirko et al. 2018) and increases the signal-to-noise ratio in CA1 by modulating CA1 inhibitory interneurons (Owen et al. 2013).

Given the connectivity of dCA2 and vCA1, their relative social specialization, and that CA2 is unnecessary for spatial memory (Hitti and Siegelbaum 2014), dCA2-vCA1 circuitry may be specialized to perform social computations (Bienkowski et al. 2018; Meira et al. 2018). Recent work suggests that dCA2 pyramidal neurons, which are necessary for social recognition encoding, consolidation, and retrieval, send excitatory projections to vCA1 pyramidal neurons that are also necessary for social recognition (Meira et al. 2018). Thus, dCA2 could act as a social information processing hub, regulated by the binding of oxytocin and vasopressin receptors, that modulates excitatory drive onto vCA1 in social information processing.

There may also be specialized ventral CA3 (vCA3) to vCA1 circuitry that contributes to social recognition. Ventral, but not dorsal, CA3 is necessary for encoding social recognition memory (Chiang et al. 2018). Given little evidence for a functional relationship between vCA3 and dCA2, projections from vCA 3 and dCA2 may form distinct pathways and integrate in vCA1 (Meira et al. 2018). vCA 3 and dCA 2 may also provide different types of social information: vCA3 is unnecessary for social memory recall, for example, suggesting dCA2-vCA1 might underpin vCA1's role in social memory retrieval. Thus, multiple specialized circuits in the hippocampus likely contribute to social relational modeling.

Circuits within the hippocampus do not act alone: The hippocampus is central within a wider network for social mapping and map-based decision-making. For example, inputs from amygdala to vCA1 affect social interaction (Felix-Ortiz and Tye 2014), perhaps by contributing infor- mation about the salience or behavioral relevance of incoming social information. Projections from vCA1 pyramidal neurons to nucleus accumbens shell are necessary for social recognition (Okuyama et al. 2016), and plasticity in this pathway modulates social reward and affiliation (Walum and Young 2018). Projections from vCA1 to medial prefrontal cortex (mPFC) are also necessary for social recognition and likely reflect social memory retrieval (Phillips et al. 2018), in agreement with a proposed role for $\mathrm{mPFC}$ in retrieving hippocampal representations to guide decision-making (Kaplan et al. 2017). Indeed, $\mathrm{mPFC}$ to dorsal periaqueductal gray circuitry directly modulates social behaviors (Franklin et al. 2017). mPFC activity also impacts the activity of the amygdala and nucleus accumbens (Öngür and Price 2000), suggesting it could regulate interactions between these regions and the hippocampus in social mapping. Network-wide distribution of oxytocin receptors is evident as well: In addition to the hippocampus, oxytocin receptors are dense in the amygdala, nucleus accumbens, and mPFC (Huber et al. 2005; Smeltzer et al. 2006; Ross et al. 2009).

\section{SOCIAL NAVIGATION}

Social behavior may be understood as an act of social navigation based upon social maps. Social information is complex and ambiguous; social maps may allow for the prediction of subsequent social information - constraining the computational complexity of social inferences and decision-making. Relational organization could underpin relational social memory, and enable simulations and predictions about others' mental states and likely actions, as well as outcomes such as social reward or social threat-in turn supporting decision-making, such as whether to engage in affiliative or social avoidance behaviors. Inaccurate maps would lead to poor or erroneous organization of social information, poor social predictions, and ultimately maladaptive social behavior. The co-occurrence of hippocampal and social dysfunction in psychiatric disorders may reflect the disruption of relational social information processing (e.g., social memory, social context, relative power, and affiliation).

As mentioned above, Tavares et al. (2015) found that hippocampal tracking of a power by affiliation social space correlated with self-reported social anxiety, suggesting that the integrity of social space mapping could relate to psychiatric symptoms. Considering others as "locations" and relationships as "trajectories" in social space offers a powerful framework to explain and make novel predictions about social dysfunction. In the text to follow, insights into the link between social dysfunction and hippocampus structure and function in four disorders (schizophrenia, autism spectrum disorder [ASD], major depressive disorder [MDD], and social anxiety disorder [SAD]) will be discussed. For each disorder, we present evidence for co-occurring social and hippocampal dysfunction, evidence directly connecting the hippocampus to social dysfunction (Table 1), and the potential explanatory power of the social mapping framework. 
Table 1. Summary of evidence for social dysfunction, hippocampal abnormalities, and work connecting social dysfunction with hippocampal abnormalities in psychiatric disorders

\begin{tabular}{|c|c|c|c|}
\hline Disorder & Social dysfunction & Hippocampal abnormalities & Social hippocampus links \\
\hline SCZ & $\begin{array}{l}\text { Social withdrawal } \\
\text { Fewer relationships } \\
\text { Impaired emotion } \\
\text { recognition } \\
\text { Impaired mentalizing } \\
\text { Failure to update social } \\
\text { reward expectancies } \\
\text { Social ambiguity interpreted } \\
\text { as social threat }\end{array}$ & $\begin{array}{l}\text { Smaller volume } \\
\text { Reduced CA3 dendritic spine density } \\
\text { Fewer GABAergic interneurons (esp. } \\
\text { in CA2) } \\
\text { White matter tract impairments in } \\
\text { fornix (major output of } \\
\text { hippocampus) } \\
\text { Hippocampal hyperactivity } \\
\text { Hippocampal functional network } \\
\text { disturbances }\end{array}$ & $\begin{array}{l}\text { Negative symptoms (incl. social withdrawal) } \\
\text { inversely correlated with hippocampal volume } \\
\text { Hippocampus activity related to emotion recognition } \\
\text { deficits } \\
\text { Mouse model: reduced CA2 inhibitory interneurons, } \\
\text { hyperactive pyramidal neurons, social memory } \\
\text { impairments }\end{array}$ \\
\hline ASD & $\begin{array}{l}\text { Social isolation } \\
\text { Impaired emotion } \\
\text { recognition } \\
\text { Impaired mentalizing } \\
\text { Using social context to } \\
\text { understand nonliteral } \\
\text { language } \\
\text { Impaired social memory }\end{array}$ & $\begin{array}{l}\text { Larger volume } \\
\text { Reduced hippocampal dendritic } \\
\text { branching } \\
\text { Reduced GABA receptor density in } \\
\text { CA1, CA2, prosubiculum, and } \\
\text { subiculum } \\
\text { Increased GABAergic interneuronal } \\
\text { cell packing in dentate gyrus, CA1, } \\
\text { CA3 } \\
\text { Reduced covariation between } \\
\text { hippocampus and PFC in episodic } \\
\text { memory }\end{array}$ & $\begin{array}{l}\text { Metabolic alterations correlated with social } \\
\text { impairment } \\
\text { White matter alterations between hippocampus and } \\
\text { mid-fusiform (face processing tract) } \\
\text { Mouse model: vCA1 to mPFC alterations in mouse } \\
\text { model correlated with social memory deficits } \\
\text { Mouse model: CA1-mPFC plasticity is reduced, } \\
\text { long-term social recognition is impaired; deficits are } \\
\text { improved with oxytocin treatment }\end{array}$ \\
\hline MDD & $\begin{array}{l}\text { Poor social decision-making } \\
\text { Poor social skills } \\
\text { Less social interaction } \\
\text { Sense of not belonging } \\
\text { Perceive hostility in } \\
\quad \text { relationships } \\
\text { Restricted social networks } \\
\text { Impaired emotion } \\
\text { recognition } \\
\text { Impaired mentalizing }\end{array}$ & $\begin{array}{l}\text { Smaller volume } \\
\text { Decreased soma size } \\
\text { Densely packed cells } \\
\text { Hippocampal functional network } \\
\text { disturbances } \\
\text { Hippocampus activity correlates with } \\
\text { episodic memory and spatial } \\
\text { navigation deficits }\end{array}$ & $\begin{array}{l}\text { Hippocampal activation during social rejection } \\
\text { Treatment normalized hippocampal activation to } \\
\text { emotional faces } \\
\text { Mouse model: hippocampus to nucleus accumbens } \\
\text { projections mediated chronic social stress and social } \\
\text { withdrawal }\end{array}$ \\
\hline SAD & $\begin{array}{l}\text { Fear of social situations } \\
\text { Fear of evaluation and } \\
\text { embarrassment } \\
\text { Difficulty maintaining } \\
\text { relationships } \\
\text { Impaired emotion } \\
\text { recognition } \\
\text { Impaired mentalizing }\end{array}$ & \multicolumn{2}{|c|}{$\begin{array}{l}\text { Volume alterations (inconclusive evidence) } \\
\text { Hippocampal hyperactivation related to: } \\
\text { negative associations with neutral faces } \\
\text { harsh facial stimuli } \\
\text { preparation for public speaking } \\
\text { mentalizing } \\
\text { emotion recognition (entorhinal and parahippocampal) } \\
\text { Treatmentreduces both social anxiety and hippocampal activity to social anxiety-inducing tasks } \\
\text { Posttreatment changes in hippocampal activity correlate with reductions in social anxiety }\end{array}$} \\
\hline
\end{tabular}

Citations are in text. This table is not meant to be exhaustive - rather it summarizes some of the evidence for co-occurrence of social and hippocampal alterations in psychiatric disorders and suggests a link between them may be based in social cognitive map-related mechanisms.

(SCZ) Schizophrenia; (ASD) autism spectrum disorder; (MDD) major depressive disorder; (SAD) social anxiety disorder.

\section{SCHIZOPHRENIA}

\section{Social Dysfunction}

Social impairments are core to schizophrenia. They precede onset, predict disease severity (Green et al. 2015), and lead to social withdrawal, including fewer relationships and a low marriage rate (Thara and Srinivasan 1997; Harley et al. 2012). Although some social impairments in schizophrenia may result from nonsocial sources (e.g., psychotic symptoms), specifically social dysfunctions are likely key to social impairments as well: Social cognitive factors explain a unique amount of variance in social skills (Pinkham and Penn 2006). For example, social inferences such as emotion recognition and mentalizing (i.e., inferring others' mental states; Bora and Pantelis 2013) are deficient in schizophrenia, occur across sensory modalities (Leitman et al. 2010; Chung et al. 2014), and correlate with real-world social functioning (Brüne 2005; Fett et al. 2011). Additionally, emotion recognition and mentalizing deficits present early and are stable over time, sometimes persisting after treatment, and exist to a lesser extent in unaffected relatives (Bediou et al. 2007; Penn et al. 2008; Bora and Pantelis 2013), suggesting that social dysfunction may be a risk factor for schizophrenia.

\section{Hippocampal Abnormalities}

Hippocampal abnormalities are also central to schizophrenia (Tamminga et al. 2010; Lodge and Grace 2011). Hippocampal volume is consistently smaller in schizophrenia (Adriano et al. 2012) along with cellular changes, such as reduced CA3 dendritic spine density (Kolomeets 
et al. 2005). Individuals with schizophrenia also have reduced inhibitory (GABAergic) interneuron populations that could dysregulate intrahippocampal excitation: Schizophrenia relates to fewer parvalbumin-expressing interneurons (Konradi et al. 2011), especially in CA2 (Knable et al. 2004; Piskorowski et al. 2016), and fewer somatostatin expressing interneurons (Konradi et al. 2011). Hippocampal activity is indeed dysregulated in schizophrenia, with hyperactivity potentially reflecting excessive CA3 pattern completion (Tamminga et al. 2010). Reduced white matter integrity in the fornix, the major hippocampal output fiber tract, could additionally impact hippocampal output in schizophrenia (Kuroki et al. 2006; Zhou et al. 2008). Such structural abnormalities likely lead to network disturbances, as evidenced by altered BOLD covariation between the hippocampal formation and regions including dorsolateral PFC (MeyerLindenberg et al. 2005), mPFC, and posterior cingulate cortex/precuneus (Zhou et al. 2008).

\section{Evidence Connecting the Hippocampus to Social Dysfunction}

Although psychotic symptoms are often effectively reduced with dopamine treatment, social withdrawal is largely unaffected (Remington et al. 2016), suggesting social impairments may be explained by hippocampal abnormalities themselves - such as volume loss that is unaltered by dopamine stabilization (Panenka et al. 2007). Consistent with this view, individuals with more prominent negative symptoms (i.e., a range of deficits that include social withdrawal) have smaller hippocampal and parahippocampal volumes (Sigmundsson et al. 2001; Wible et al. 2001; Anderson et al. 2002). Meta-analysis reveals that less hippocampus activity is related to emotion recognition deficits in schizophrenia (Taylor et al. 2012). Further, plasma oxytocin and anterior hippocampus volume are inversely correlated in schizophrenia, and oxytocin levels predict emotion recognition abilities (Goldman et al. 2008). A mouse model of a genetic risk factor for schizophrenia provides more granular evidence: The genetic microdeletion of $22 \mathrm{q} 11.2$ severely impacts social recognition, likely because of reduced CA2 parvalbumin interneuron density and inhibitory signaling and neuronal hyperpolarization that effectively silences CA2 pyramidal neurons even under direct stimulation (Piskorowski et al. 2016).

\section{Putative Social Mapping Impairment: Impoverished Maps}

Given the evidence for a specific CA2 circuit deficit in schizophrenia, it may be that social relational modeling within the hippocampus itself is impaired: Schizophreniarelated reductions in CA2 inhibitory interneurons hyperpolarize CA2 pyramidal neurons (Piskorowski et al. 2016) and could impair the integration of relational social information into larger relational frameworks. Social information is often ambiguous and continuous, and its efficient use necessitates both extensive relational organization and flexible updating. Individuals with schizophrenia may be impaired in both forming and updating social relational representations - especially as information becomes more abstract (i.e., not reducible to immediate sensory experience), and relational inferences become more complex. Schizophrenia impairments in inferring what others are thinking (i.e., mentalizing) are more pronounced than impairments in inferring what others are doing (Penn et al. 2008) and are related to impairments in using relational information (Uhlhaas et al. 2006). Additionally, schizophrenia impairments in learning and relating information within and across social tasks increase with the complexity of relationships (Penn et al. 2008).

CA2 hyperpolarization combined with aberrant and illusory relational binding in CA3 due to "runaway" pattern completion (Tamminga et al. 2010) could lead to social relational representations and predictions that are both inaccurate and resistant to updating - maps that are impoverished and inflexible. Such relational structures could explain imprecise inferences in schizophrenia: Individuals with schizophrenia report inaccurate interpretations of both social scenes and social faces and tend to view even ambiguous social stimuli as threatening (Phillips et al. 2000).

Social prediction errors also fail to update social expectations: Despite having rewarding social experiences, individuals with schizophrenia do not update expectations for future social reward (Kring and Caponigro 2010), perhaps reflecting an inability to induce plasticity in posterior CA2 to anterior CA1 to nucleus accumbens circuitry (dCA2-vCA1-nucleus accumbens in rodents) and link social maps with reward. Indeed, individuals with schizophrenia show progressively smaller hippocampal and nucleus accumbens volumes over time, relative to controls (Wang et al. 2008). Such impoverished social mapping mechanisms may lead to social rigidity in schizophrenia and help to explain social dysfunction, such as social withdrawal.

\section{AUTISM SPECTRUM DISORDER}

\section{Social Dysfunction}

ASD prominently features social interaction deficits. Individuals with ASD ineffectively regulate social interactions, show a lack of social reciprocity, and experience social isolation (Baron-Cohen et al. 1985; Dawson et al. 2005; Leekam 2016). Frequently identified social cognitive impairments in ASD are diverse: They include emotion recognition (Harms et al. 2010), mentalizing (Chung et al. 2014), using social context to understand nonliteral language (Krasny et al. 2003), and impairments in social memory for faces and social scenes (Williams et al. 2005).

\section{Hippocampal Abnormalities}

Larger hippocampal volumes are often observed in ASD (Schumann et al. 2004; Groen et al. 2010), with hippocampal malformations potentially associated with increased 
seizure risk (Dager et al. 2007), suggesting functional disturbances directly result from ASD hippocampal structural abnormalities. Consistent with increased seizure risk, ASD excitatory-inhibitory balance in the hippocampus may be abnormal. Research shows reduced hippocampal neuronal cell body size and dendritic branching (Raymond et al. 1996) along with subfield specific GABAergic alterations, such as reduced GABA receptor density (Guptill et al. 2007), especially in CA1, CA2, prosubiculum, and subiculum (Blatt et al. 2001), and increased GABAergic interneuronal cell packing in hippocampal subregions dentate gyrus, CA1, and CA3 (Lawrence et al. 2010). Hippocampal abnormalities may have direct cognitive consequences in ASD, such as reduced covariation between the hippocampus and prefrontal regions that relates to memory retrieval failure (Cooper et al. 2017).

\section{Evidence Connecting the Hippocampus to Social Dysfunction}

Although relatively little research has directly related the hippocampus to social function in ASD, several indications suggest more work is needed. Individuals with ASD have metabolic abnormalities in the hippocampus that correlate with social impairment (Endo et al. 2007), and white matter tracts are altered between the hippocampus and mid-fusiform gyrus, a pathway important to face processing (Conturo et al. 2008). In a mouse model of ASD, hyperactivity of vCA1 (anterior in humans) to prelimbic $\mathrm{mPFC}$ projections relate to impaired social memory (Phillips et al. 2018), suggesting posterior CA2 to anterior CA1 (dCA2-vCA1 in rodents) to mPFC circuitry may be relevant to ASD etiology. Indeed, in another animal model, a synaptic gene (SHANK3) mutation that commonly results in ASD diagnosis reduced synaptic plasticity in a CA1-prelimbic mPFC pathway and selectively impaired long-term social memory - deficits that were reduced with oxytocin administration (Harony-Nicolas et al. 2017).

\section{Putative Social Mapping Impairment: Restricted Mapping}

Oxytocin deficiency in ASD could increase neuronal noise in the hippocampus, impair hippocampal processing, and restrict the range of information encoded into maps. Deficient oxytocin binding in the hippocampus could be relevant to ASD, given associations between ASD and the oxytocin receptor gene (LoParo and Waldman 2015), reduced hippocampal oxytocin receptor expression in animal models of ASD (Peñagarikano 2017), and the efficacy of intranasal oxytocin in improving ASD's social impairments (Anagnostou et al. 2014). Oxytocinergic impairments in the CA2-CA1 circuit could manifest as impairments in social relational modeling, as well as general impairments in hippocampal mapping, via reduced signal and increased noise in CA1 (Owen et al. 2013).

Modeling is computationally expensive; as the relationships between task elements become more complex, the demands on hippocampal processing might increase (e.g., greater need for spatial and temporal integration of many weak signals): In the case of noisy information processing, background noise may overwhelm signal and statistical mapping processes may break down. Only very robust and regular signals would be reliably encoded, restricting the range of relational structures that can be mapped, stored, and retrieved successfully (e.g., by mPFC) without interference from other maps. Indeed, individuals with ASD have impaired recollection for social stimuli, as well as for other complex stimuli (Williams et al. 2005), and other work shows memory in ASD decreases as a function of task complexity (Minshew and Goldstein 2001).

A restricted mapping range may restrict social cognition and the range of available behaviors, as well as contribute to other restricted behavioral patterns in ASD. Oxytocin treatment, then, would have the potential to improve hippocampal signal-to-noise ratio and social mapping, and lead to better hippocampal map decoding by downstream regions. Such improvements would be reflected in enhanced hippocampal network covariation during hippocampal-dependent behaviors and correlate with improvements in social functions (e.g., social memory), especially when organizing complex information. Consistent with this possibility, oxytocin administration increased mPFC fMRI signal in a double-blinded, placebo-controlled ASD trial, which in turn led to improvements in the individual's ability to make accurate social inferences under situations of conflicting social information (Aoki et al. 2015). Thus, constrained mapping in the hippocampus has the potential to explain some social impairments in ASD: Restricted mapping may produce restricted social behaviors.

\section{MAJOR DEPRESSIVE DISORDER}

\section{Social Dysfunction}

MDD has a large impact on social functioning: Common dysfunction includes poor social decision-making (Goddard et al. 1997), poor social skills (Segrin 2000), a sense of not belonging (Hagerty et al. 1996), fewer social interactions (De Choudhury et al. 2013), and relationship difficulty, leading to eventual social isolation (Segrin 2000). Social dysfunction can precede and exacerbate other depressive symptoms (Joiner and Timmons 2002) and even predict suicidal behavior in MDD: Suicide attempters think of social problems as intractable, perceive hostility and a lack of social support in their relationships, and have restricted social networks (Szanto et al. 2012). A mechanistic understanding of social cognitive deficits in MDD is needed: Basic cognitive processes (e.g., attention) do not sufficiently explain social dysfunction in MDD (Ladegaard et al. 2014; Bora and Berk 2016), and social deficits persist even after other depressive symptoms recover (Rhebergen et al. 2010). Individuals with MDD are impaired in mentalizing (Wolkenstein et al. 2011) and have a negativity bias in emotion recognition, whereby faces are perceived as more negative (e.g., sad) than healthy controls perceive them (Fu et al. 2008). 


\section{Hippocampal Abnormalities}

One of the most replicated neurobiological findings in MDD is the altered shape and smaller volume of the hippocampus (Cole et al. 2011). Smaller volumes may be explained by cellular abnormalities, such as decreased pyramidal soma size and more densely packed pyramidal, granule, and glia cells relative to controls (Stockmeier et al. 2004). Further, networks that include the hippocampus are often dysregulated in MDD (MacQueen and Frodl 2011), including altered covariation with the amygdala and prefrontal cortex (PFC) (Drevets et al. 2008), as well as greater covariation with the default mode network, a set of regions implicated in self- and other-referential thinking that includes the mPFC (Kaiser et al. 2015). Hippocampal abnormalities in MDD have cognitive consequences: Individuals with MDD show hippocampus-related deficits in both episodic memory (Lee et al. 2012) and spatial navigation (Cornwell et al. 2010). The clinical significance of hippocampal changes is clear: Smaller volume is correlated with clinical variables such as childhood abuse, younger age of illness onset, longer time untreated, greater symptom severity, illness burden, and worse treatment outcome (MacQueen and Frodl 2011).

\section{Evidence Connecting the Hippocampus to Social Dysfunction}

Hippocampal alterations in MDD have been linked to social dysfunction and withdrawal. Specifically, increased sensitivity to negative social information in MDD relates to hippocampal processing, and social rejection relates to abnormally increased amygdala and parahippocampal gyrus activity (Silk et al. 2017). Additionally, chronic social stress induces social withdrawal via hippocampal projections to nucleus accumbens, as shown by a mouse model of depression (Bagot et al. 2015). Impaired hippocampal representations may be crucial in these social deficits: A lack of episodic memory specificity mediates the relationship between depressive rumination and social decisionmaking deficits (Raes et al. 2005). Supporting this view, effective treatment of MDD often normalizes hippocampus signal during social functions. For example, after treatment with selective serotonin reuptake inhibitors (SSRIs), which often leads to hippocampal changes (Dale et al. 2016), or cognitive behavioral therapy (Fu et al. 2007, 2008), symptom improvements correlate with the normalization of hippocampal response to emotional faces. Further, experimentally increasing hippocampal acetylcholine activity decreases social interaction in mice, which is reversed by SSRI administration (Mineur et al. 2013), suggesting that hippocampal activity associated with MDD are directly related to social behavior.

\section{Putative Social Mapping Impairment: Fuzzy Maps}

Hippocampal pattern separation may explain commonly observed deficits in episodic memory specificity in MDD (i.e., increased vagueness in memory recall; Eisch and Petrik 2012) and may also be relevant in MDD social mapping - ultimately by increasing feelings of social distance. What differentiates close loved ones from distant strangers is a shared history of reciprocity, common interests, knowledge of the other's idiosyncrasies, and so on. Impaired social map pattern separation would impair retrieval of that shared history: Maps that relate to specific individuals would be more difficult to disambiguate and retrieve. Impairments in social map differentiation could cause even family members and romantic partners to seem socially distant. Social distance seems implicated in a variety of social deficits in MDD, including perceptions of hostility in interactions, inadequate social support in current relationships (Szanto et al. 2012), and not belonging socially (Hagerty et al. 1996).

Feelings of social distance in MDD may result in part from poor $\mathrm{mPFC}$ retrieval of hippocampal social maps. $\mathrm{mPFC}$, a key region in self- and other judgments (Denny et al. 2012) and in using hippocampal representations to guide decision-making (Kaplan et al. 2017), could compute social proximity from hippocampal social map readouts. When mPFC fails to retrieve specific social maps that relate individuals to relevant social information, it may default to representing others as unaffiliated.

Such difficulties in map separation and retrieval might also explain MDD deficits in mentalizing (Wolkenstein et al. 2011): The generalization of hippocampal maps in mentalization is guided by the perceived similarity between self and others (Perry et al. 2011) — and poor map separation could impair the specificity of social simulations (Williams et al. 1996). In support of this hypothesis, reduced memory specificity in MDD correlated with reduced covariation of posterior cingulate cortex with nearby regions (Zhu et al. 2012) - posterior cingulate cortex being an area implicated (along with $\mathrm{mPFC}$ ) in default mode self- and other processing (Schilbach et al. 2008) and in mapping social distance (Tavares et al. 2015).

Impaired map pattern separation would also impair the ability to link relational representations of specific individuals with social reward: Decreases in social bonding (i.e., affiliation) could relate to reduced connectivity between maps in anterior CA1 (vCA1 in rodents) and nucleus accumbens (Walum and Young 2018). Individuals undergoing MDD experience a loss of reward from positive social interactions along with hypoactive nucleus accumbens (Hsu et al. 2015), and they tend to develop a less intimate social network (Szanto et al. 2012) and maintain fewer relationships (Segrin 2000). The social relational view might further suggest an explanation for selfrelated rumination in MDD, via altered hippocampal and mPFC interactions (Cooney et al. 2010): When others are perceived as distant and feelings of social isolation increase, thoughts may increasingly turn inward.

\section{SOCIAL ANXIETY DISORDER}

\section{Social Dysfunction}

Social phobia is the central clinical feature of SAD (Liebowitz et al. 1985). During social situations, individuals 
with SAD feel fear of social evaluation and embarrassment and experience co-occurring physical symptoms, such as increased heart rate and sweating (Stein and Stein 2008). As a result, individuals struggle to maintain relationships, have difficulties advancing their education or careers, and at times avoid social interaction altogether (Liebowitz et al. 1985; Stein and Stein 2008).

\section{Evidence Connecting the Hippocampus to Social Dysfunction}

Evidence of altered hippocampal function during social anxiety in SAD is relatively strong: Research has consistently implicated increased hippocampus signal in social phobia - an abnormality that is normalized by effective treatment. For example, individuals with SAD report greater social anxiety and show greater parahippocampus/hippocampus and amygdala activation to negative associations with neutral faces (Schneider et al. 1999) and harsh facial stimuli (Stein et al. 2002; Goldin et al. 2009) but show no differences from controls when viewing physical threat (Goldin et al. 2009). Social behaviors increase social anxiety and parahippocampus/hippocampus activity, such as public speaking (Tillfors et al. 2002), as do expectation of social behaviors, such as preparing for public speaking (Lorberbaum et al. 2004).

Interpreting the mental states of others also causes hyperactivity in the hippocampal formation in SAD. For example, SAD is associated with abnormal activity increases in the hippocampus during mentalizing (Sripada et al. 2009) and in the parahippocampus and entorhinal cortex during emotion recognition (Hattingh et al. 2013). Effective treatment of SAD often normalizes hippocampal function, consistent with a prominent role for the hippocampus in SAD. Serotonin manipulations (Furmark et al. 2002, 2005; Kilts et al. 2006) and cognitive behavioral therapy (Furmark et al. 2002) both reduce social anxiety and normalize hippocampus, parahippocampus, and amygdala fMRI signal in individuals with SAD during social anxiety inducing tasks. Posttreatment changes in the hippocampus persist and correlate with posttreatment reductions in clinical measures of social anxiety for several weeks (Furmark et al. 2005), up to one year (Furmark et al. 2002) or longer - evidence that long-term improvement in clinical symptoms in SAD depends partially upon normalizing hippocampal function.

\section{Putative Social Mapping Impairment: Biased Simulations}

Individuals with SAD selectively attend to, fear and avoid sources of potential social threat, a process that could include hippocampal map-based simulations of social threat and avoidance. Hippocampal mapping is sensitive to the current behavioral goal of the animal. Similar to how reward location is represented and guides reward-motivated animals' place cell simulations and decision-making, social threat (e.g., threat of evaluation) may be overrepresented in SAD social mapping (e.g., via overgeneralization from past social experience), and bias simulations of social situations toward negative social outcome predictions (e.g., embarrassment). The bias toward simulating negative social outcomes could help explain SAD inaccuracy in emotion recognition (Hattingh et al. 2013) and mentalizing (Sripada et al. 2009). Thus, hippocampal mapping may ultimately inform social avoidance behaviors in SAD: The hippocampus may chart out "safe" trajectories by which an individual can avoid the threat of social evaluation. Increased hippocampal activity in SAD could reflect hyperactive social simulations, negative outcome predictions, and planning of social avoidance trajectories. As research on hippocampal structure in SAD is mixed, with studies showing greater gray matter volume (Machado-deSousa et al. 2014), less gray matter volume (Irle et al. 2010), and no difference (Syal et al. 2012), it is possible such biased simulations reflects impairments within the hippocampus and/or impairments within a larger network - for example, between the hippocampus, amygdala, and mPFC (Tovote et al. 2015). Mapping itself may be biased, or mapping may be largely preserved, and how maps are used in social simulations, predictions, and decision-making may be the source of the bias.

\section{DISCUSSION AND FUTURE DIRECTIONS}

Evidence is consistent with links between hippocampal and social dysfunction across psychiatric disorders, including schizophrenia, MDD, SAD, and ASD. Although we believe social mapping deficits may explain these links, we are not claiming that hippocampal dysfunction necessarily leads to social dysfunction, that all social dysfunction reflects hippocampal dysfunction, or that the same impairments must exist in all cases of social hippocampus problems (Fig. 1). Instead, the evidence suggests that specific social symptoms may be explained by hippocampus dysfunction or hippocampal interactions with other regions (e.g., amygdala, $\mathrm{mPFC}$ ), and a variety of map-related impairments could be implicated. For example, relational modeling itself may be impaired; poor map separation and aberrant map completion could lead to inaccurate social inferences and maladaptive social decision-making; social map-based simulations may be biased toward particular behavioral goals; and so on.

A transdiagnostic social mapping perspective may clarify the mechanisms underlying social symptom overlap in different disorders. For example, social anxiety occurs across disorders, including ASD (Bellini 2006), MDD, and schizophrenia (Schneier et al. 1992), and may have a common cause in social map-based simulations of negative social outcomes. Microdeletion of 22q11.2 causes CA2 and social memory impairments and is associated with both schizophrenia and ASD diagnosis (Piskorowski et al. 2016); however, schizophrenia is associated with reduced hippocampal volume, whereas ASD is associated with increased hippocampal volume. Thus, although their symptoms may be similar, the mechanisms that underlie those symptoms might differ. Oxytocin and vasopressin binding in the hippocampus could additionally hold spe- 


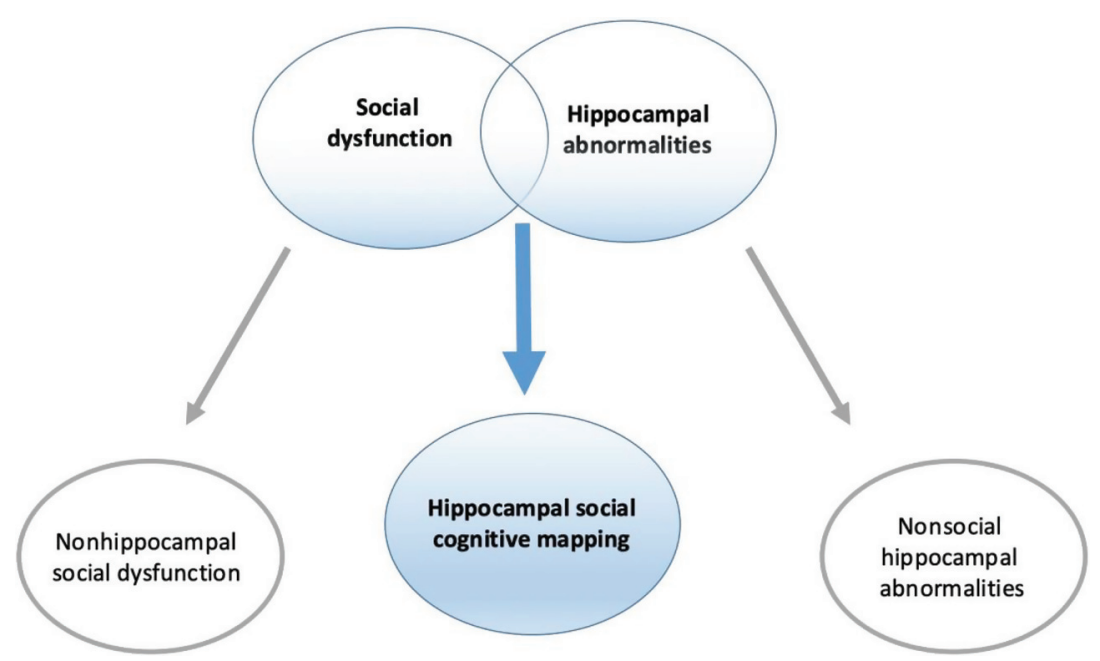

Figure 1. The basic logic of the link between social and hippocampus evidence. The claims made in this review reflect the schematic above: Although we are claiming that some co-occurrence of social dysfunction and hippocampal abnormalities may be linked in hippocampal social cognitive mapping, we are not claiming that this is true in all cases. Note that arrows do not imply causal direction.

cial relevance and explain social information processing deficits across disorders.

A cumulative research program could help resolve the mechanisms of hippocampal social mapping and dysfunction. Ecologically valid experiments are needed to provide further evidence for a link between the hippocampus, social mapping, and social behavior. For example, dynamic tasks are needed to manipulate and measure the interplay between social memory, social predictions, prediction errors, and decision-making; relating and using social information across social contexts; the detection of context-specific social emotions that cannot be decoded from facial expression alone (e.g., shame); and social interactions/relationships that unfold over time.

To characterize hippocampal functions, several considerations should be held in view. Improved spatial resolution may help resolve the contributions of hippocampal subregions to social functions. Patterns of activation may provide more information than mean activation alone, and spatially and temporally distributed signals (e.g., oscillatory activity in magnetoencephalography, dynamic causal modeling in fMRI) may clarify the role of hippocampal representations within larger networks: Problems in social cognitive mapping could occur anywhere within input, central processing, or output structures. As several regions (e.g., posterior cingulate cortex/precuneus, dorsolateral PFC, and inferior parietal lobule) track components of social vectors to others in social space (Tavares et al. 2015), social mapping dysfunction likely results from impairments within a broader network.

Longitudinal research with repeated measures is necessary to account for compensatory processes and plasticity, to track hippocampal structural and functional changes in relation to social cognition and behavior, and to discover predictors for risk and treatment efficacy. Behavioral indices sensitive to hippocampus-mediated social mapping may allow accurate diagnosis of real-world social dys- function in a cost-effective manner. Interventions additionally may be informed by a social mapping point of view. This includes interventions during development designed to reduce the potential for social stress to sculpt the social mind: Positive social interactions after social stress may mitigate social stress-related changes, including social behavioral changes (Isovich et al. 2001). Thus, for adolescents undergoing severe social stress, careful attention should be paid to social dynamics (e.g., power and affiliation), given the possibility of a social sensitive period in social mapping.

The social mapping perspective offers the potential for great explanatory power in psychiatry and neuroscience: It is transdiagnostic and dimensional, with specific hypotheses about computational and neurobiological substrates. It suggests ways to improve diagnosis and interventions, informed by a precise view of how relational social cognition may operate. Indeed, social mapping offers the chance for a mechanistic account of social cognition and dysfunction - and to answer core questions about the importance of social relations.

\section{ACKNOWLEDGMENTS}

Funding was provided by the Klingenstein-Simons Fellowship Award in the Neurosciences to D.S. and by NIA T32AG049688 to M.S.

\section{REFERENCES}

Adriano F, Caltagirone C, Spalletta G. 2012. Hippocampal volume reduction in first-episode and chronic schizophrenia: a review and meta-analysis. Neuroscientist 18: 180-200. doi: $10.1177 / 1073858410395147$

Alexander GM, Farris S, Pirone JR, Zheng C, Colgin LL, Dudek SM. 2016. Social and novel contexts modify hippocampal CA2 representations of space. Nat Commun 7: 10300. doi:10 $.1038 /$ ncomms 10300 
Aly M, Knight RT, Yonelinas AP. 2010. Faces are special but not too special: spared face recognition in amnesia is based on familiarity. Neuropsychologia 48: 3941-3948. doi:10.1016/j .neuropsychologia.2010.09.005

Anagnostou E, Soorya L, Brian J, Dupuis A, Mankad D, Smile S, Jacob S. 2014. Intranasal oxytocin in the treatment of autism spectrum disorders: a review of literature and early safety and efficacy data in youth. Brain Res 1580: 188-198. doi:10.1016/ j.brainres.2014.01.049

Anderson JE, Wible CG, McCarley RW, Jakab M, Kasai K, Shenton ME. 2002. An MRI study of temporal lobe abnormalities and negative symptoms in chronic schizophrenia. Schizophr Res 58: 123-134. doi:10.1016/S0920-9964(01)00372-3

Aoki Y, Watanabe T, Abe O, Kuwabara H, Yahata N, Takano Y, Iwashiro N, Natsubori T, Takao H, Kawakubo Y, et al. 2015. Oxytocin's neurochemical effects in the medial prefrontal cortex underlie recovery of task-specific brain activity in autism: a randomized controlled trial. Mol Psychiatry 20: 447-453. doi:10.1038/mp.2014.74

Bagot RC, Parise EM, Peña CJ, Zhang H-X, Maze I, Chaudhury D, Persaud B, Cachope R, Bolaños-Guzmán CA, Cheer JF, et al. 2015. Ventral hippocampal afferents to the nucleus accumbens regulate susceptibility to depression. Nat Commun 6: 7062 . doi: $10.1038 /$ ncomms 8062

Baron-Cohen S, Leslie AM, Frith U. 1985. Does the autistic child have a "theory of mind"? Cognition 21: 37-46. doi:10.1016/ 0010-0277(85)90022-8

Bediou B, Asri F, Brunelin J, Krolak-Salmon P, D'Amato T, Saoud M, Tazi I. 2007. Emotion recognition and genetic vulnerability to schizophrenia. Br J Psychiatry 191: 126-130. doi:10.1192/bjp.bp.106.028829

Behrens TEJ, Muller TH, Whittington JCR, Mark S, Baram AB, Stachenfeld KL, Kurth-Nelson Z. 2018. What is a cognitive map? Organizing knowledge for flexible behavior. Neuron 100: 490-509. doi:10.1016/j.neuron.2018.10.002

Bellini S. 2006. The development of social anxiety in adolescents with autism spectrum disorders. Focus Autism Other Dev Disabl 21: 138-145. doi:10.1177/10883576060210030201

Bellmund JLS, Gärdenfors P, Moser EI, Doeller CF. 2018. Navigating cognition: spatial codes for human thinking. Science 362: eaat6766. doi:10.1126/science.aat6766

Bienkowski MS, Bowman I, Song MY, Gou L, Ard T, Cotter K, Zhu M, Benavidez NL, Yamashita S, Abu-Jaber J, et al. 2018. Integration of gene expression and brain-wide connectivity reveals the multiscale organization of mouse hippocampal networks. Nat Neurosci 21: 1628-1643. doi:10.1038/s41593018-0241-y

Bird CM, Shallice T, Cipolotti L. 2007. Fractionation of memory in medial temporal lobe amnesia. Neuropsychologia 45: 11601171. doi:10.1016/j.neuropsychologia.2006.10.011

Blatt GJ, Fitzgerald CM, Guptill JT, Booker AB, Kemper TL, Bauman ML. 2001. Density and distribution of hippocampal neurotransmitter receptors in autism: an autoradiographic study. J Autism Dev Disord 31: 537-543. doi:10.1023/A:101 3238809666

Bora E, Berk M. 2016. Theory of mind in major depressive disorder: a meta-analysis. J Affect Disord 191: 49-55. doi:10 $.1016 /$ j.jad.2015.11.023

Bora E, Pantelis C. 2013. Theory of mind impairments in firstepisode psychosis, individuals at ultra-high risk for psychosis and in first-degree relatives of schizophrenia: systematic review and meta-analysis. Schizophr Res 144: 31-36. doi:10 .1016/j.schres.2012.12.013

Brent LJN, Heilbronner SR, Horvath JE, Gonzalez-Martinez J, Ruiz-Lambides A, Robinson AG, Pate Skene JH, Platt ML. 2013. Genetic origins of social networks in rhesus macaques. Sci Rep 3: 1-8.

Brüne M. 2005. Emotion recognition, "theory of mind," and social behavior in schizophrenia. Psychiatry Res 133: 135147. doi:10.1016/j.psychres.2004.10.007

Chiang MC, Huang AJY, Wintzer ME, Ohshima T, McHugh TJ. 2018. A role for CA3 in social recognition memory. Behav Brain Res 354: 22-30. doi:10.1016/j.bbr.2018.01.019
Chung YS, Barch D, Strube M. 2014. A meta-analysis of mentalizing impairments in adults with schizophrenia and autism spectrum disorder. Schizophr Bull 40: 602-616. doi:10.1093/ schbul $/$ sbt048

Cole J, Costafreda SG, McGuffin P, Fu CHY. 2011. Hippocampal atrophy in first episode depression: a meta-analysis of magnetic resonance imaging studies. J Affect Disord 134: 483-487. doi:10.1016/j.jad.2011.05.057

Colgin LL, Moser EI, Moser MB. 2008. Understanding memory through hippocampal remapping. Trends Neurosci 31: 469477. doi:10.1016/j.tins.2008.06.008

Constantinescu AO, O'Reilly JX, Behrens TEJ. 2016. Organizing conceptual knowledge in humans with a gridlike code. Science 352: 1464-1468. doi:10.1126/science.aaf0941

Conturo TE, Williams DL, Smith CD, Gultepe E, Akbudak E, Minshew NJ. 2008. Neuronal fiber pathway abnormalities in autism: an initial MRI diffusion tensor tracking study of hippocampo-fusiform and amygdalo-fusiform pathways. J Int Neuropsychol Soc 14: 933. doi:10.1017/S135561770808 1381

Cooney RE, Joormann J, Eugène F, Dennis EL, Gotlib IH. 2010. Neural correlates of rumination in depression. Cogn Affect Behav Neurosci 10: 470-478. doi:10.3758/CABN.10 .4 .470

Cooper RA, Richter FR, Bays PM, Plaisted-Grant KC, BaronCohen S, Simons JS. 2017. Reduced hippocampal functional connectivity during episodic memory retrieval in autism. Cereb Cortex 27: 888-902. doi:10.1093/cercor/bhw417

Cornwell BR, Salvadore G, Colon-Rosario V, Latov DR, Holroyd T, Carver FW, Coppola R, Manji HK, Zarate CA Jr, Grillon C. 2010. Abnormal hippocampal functioning and impaired spatial navigation in depressed individuals. Am J Psychiatry 167: 836-844. doi:10.1176/appi.ajp.2009.09050614

Croft KE, Duff MC, Kovach CK, Anderson SW, Adolphs R, Tranel D. 2010. Detestable or marvelous? Neuroanatomical correlates of character judgments. Neuropsychologia 48: 1789-1801. doi:10.1016/j.neuropsychologia.2010.03.001

Dager SR, Wang L, Friedman SD, Shaw DW, Constantino JN, Artru AA, Dawson G, Csernansky JG. 2007. Shape mapping of the hippocampus in young children with autism spectrum disorder. AJNR Am J Neuroradiol 28: 672-677.

Dale E, Pehrson AL, Jeyarajah T, Li Y, Leiser SC, Smagin G, Olsen CK, Sanchez C. 2016. Effects of serotonin in the hippocampus: how SSRIs and multimodal antidepressants might regulate pyramidal cell function. CNS Spectr 21: 143-161. doi:10.1017/S1092852915000425

Danjo T, Toyoizumi T, Fujisawa S. 2018. Spatial representations of self and other in the hippocampus. Science 359: 213-218. doi:10.1126/science.aao3898

Davachi L, DuBrow S. 2015. How the hippocampus preserves order: the role of prediction and context. Trends Cogn Sci 19: 92-99. doi:10.1016/j.tics.2014.12.004

Davidson PSR, Drouin H, Kwan D, Moscovitch M, Rosenbaum RS. 2012. Memory as social glue: close interpersonal relationships in amnesic patients. Front Psychol 3: 1-9.

Dawson G, Webb SJ, McPartland J. 2005. Understanding the nature of face processing impairment in autism: insights from behavioral and electrophysiological studies. Dev Neuropsychol 27: 403-424. doi:10.1207/s15326942dn2703_6

De Choudhury M, Gamon M, Counts S, Horvitz E. 2013. Predicting depression via social media. ICWSM 13: 1-10.

Denny BT, Kober H, Wager TD, Ochsner KN. 2012. A metaanalysis of functional neuroimaging studies of self- and other judgments reveals a spatial gradient for mentalizing in medial prefrontal cortex. J Cogn Neurosci 24: 1742-1752. doi:10 .1162/jocn_a_00233

Deshmukh S $\bar{S}, \bar{K}$ Knierim JJ. 2013. Influence of local objects on hippocampal representations: landmark vectors and memory. Hippocampus 267: 253-267. doi:10.1002/hipo.22101

Drevets WC, Price JL, Furey ML. 2008. Brain structural and functional abnormalities in mood disorders: implications for neurocircuitry models of depression. Brain Struct Funct 213: 93-118. doi:10.1007/s00429-008-0189-x 
Eichenbaum H. 2014. Time cells in the hippocampus: a new dimension for mapping memories. Nat Rev Neurosci 15: 732-744. doi:10.1038/nrn3827

Eisch AJ, Petrik D. 2012. Depression and hippocampal neurogenesis. Science 338: 72-75. doi:10.1126/science.1222941

Endo T, Shioiri T, Kitamura H, Kimura T, Endo S, Masuzawa N, Someya T. 2007. Altered chemical metabolites in the amygdala-hippocampus region contribute to autistic symptoms of autism spectrum disorders. Biol Psychiatry 62: 1030-1037. doi:10.1016/j.biopsych.2007.05.015

Felix-Ortiz AC, Tye KM. 2014. Amygdala inputs to the ventral hippocampus bidirectionally modulate social behavior. $J \mathrm{Neu}$ rosci 34: 586-595. doi:10.1523/JNEUROSCI.4257-13.2014

Fett AKJ, Viechtbauer W, Dominguez MD, Penn DL, van Os J, Krabbendam L. 2011. The relationship between neurocognition and social cognition with functional outcomes in schizophrenia: a meta-analysis. Neurosci Biobehav Rev 35: 573-588. doi:10.1016/j.neubiorev.2010.07.001

Fiske ST. 2012. Journey to the edges: social structures and neural maps of inter-group processes. Br J Soc Psychol 51: 1-12. doi:10.1111/j.2044-8309.2011.02092.x

Franklin TB, Silva BA, Perova Z, Marrone L, Masferrer ME, Zhan Y, Kaplan A, Greetham L, Verrechia V, Halman A, et al. 2017. Prefrontal cortical control of a brainstem social behavior circuit. Nat Neurosci 20: 260-270. doi:10.1038/nn .4470

Fu CHY, Williams SCR, Brammer MJ, Suckling J, Kim J, Cleare AJ, Walsh ND, Mitterschiffthaler MT, Andrew CM, Pich EM, et al. 2007. Neural responses to happy facial expressions in major depression following antidepressant treatment. Am J Psychiatry 164: 599-607. doi:10.1176/ajp.2007.164.4.599

Fu CHY, Williams SCR, Cleare AJ, Scott J, Mitterschiffthaler MT, Walsh ND, Donaldson C, Suckling J, Andrew C, Steiner $\mathrm{H}$, et al. 2008. Neural responses to sad facial expressions in major depression following cognitive behavioral therapy. Biol Psychiatry 64: 505-512. doi:10.1016/j.biopsych.2008.04.033

Furmark T, Tillfors M, Marteinsdottir I, Fischer H, Pissiota A, Långström B, Fredrikson M. 2002. Common changes in cerebral blood flow in patients with social phobia treated with citalopram or cognitive-behavioral therapy. Arch Gen Psychiatry 59: 425-433. doi:10.1001/archpsyc.59.5.425

Furmark T, Appel L, Michelgård Å, Wahlstedt K, Åhs F, Zancan S, Jacobsson E, Flyckt K, Grohp M, Bergström M, et al. 2005. Cerebral blood flow changes after treatment of social phobia with the neurokinin-1 antagonist GR205171, citalopram, or placebo. Biol Psychiatry 58: 132-142. doi:10.1016/j.biopsych 2005.03.029

Gauthier JL, Tank DW. 2018. A dedicated population for reward coding in the hippocampus. Neuron 99: 179-193.e7. doi:10 $.1016 /$ j.neuron.2018.06.008

Goddard L, Dritschel B, Burton A. 1997. Social problem solving and autobiographical memory in non-clinical depression. $B r J$ Clin Psychol 36: 449-451. doi:10.1111/j.2044-8260.1997 .tb01252.x

Gold AE, Kesner RP. 2005. The role of the CA3 subregion of the dorsal hippocampus in spatial pattern completion in the rat. Hippocampus 814: 808-814. doi:10.1002/hipo.20103

Goldin PR, Manber T, Hakimi S, Canli T, Gross JJ. 2009. Neural bases of social anxiety disorder: emotional reactivity and cognitive regulation during social and physical threat. Arch Gen Psychiatry 66: 170-180. doi:10.1001/archgenpsychiatry.2008 .525

Goldman M, Marlow-O'Connor M, Torres I, Carter CS. 2008. Diminished plasma oxytocin in schizophrenic patients with neuroendocrine dysfunction and emotional deficits. Schizophr Res 98: 247-255. doi:10.1016/j.schres.2007.09.019

Green MF, Horan WP, Lee J. 2015. Social cognition in schizophrenia. Nat Rev Neurosci 16: 620-631. doi:10.1038/nrn4005

Groen W, Teluij M, Buitelaar J, Tendolkar I. 2010. Amygdala and hippocampus enlargement during adolescence in autism. $\mathrm{J} \mathrm{Am}$ Acad Child Adolesc Psychiatry 49: 552-560.

Guptill JT, Booker AB, Gibbs TT, Kemper TL, Bauman ML, Blatt GJ. 2007. [ $\left.{ }^{3} \mathrm{H}\right]$-flunitrazepam-labeled benzodiazepine binding sites in the hippocampal formation in autism: a multiple concentration autoradiographic study. J Autism Dev Disord 37: 911-920. doi:10.1007/s10803-006-0226-7

Hafting T, Fyhn M, Molden S, Moser MB, Moser EI. 2005. Microstructure of a spatial map in the entorhinal cortex. Nature 436: 801-806. doi:10.1038/nature03721

Hagerty BM, Williams RA, Coyne JC, Early MR. 1996. Sense of belonging and indicators of social and psychological functioning. Arch Psychiatr Nurs 10: 235-244. doi:10.1016/S08839417(96)80029-X

Harley EWY, Boardman J, Craig T. 2012. Friendship in people with schizophrenia: a survey. Soc Psychiatry Psychiatr Epidemiol 47: 1291-1299. doi:10.1007/s00127-011-0437-x

Harms MB, Martin A, Wallace GL. 2010. Facial emotion recognition in autism spectrum disorders: a review of behavioral and neuroimaging studies. Neuropsychol Rev 20: 290-322. doi:10 1007/s11065-010-9138-6

Harony-Nicolas H, Kay M, du Hoffmann J, Klein ME, BozdagiGunal O, Riad M, Daskalakis NP, Sonar S, Castillo PE, Hof PR, et al. 2017. Oxytocin improves behavioral and electrophysiological deficits in a novel Shank3-deficient rat. eLife 6: e18904. doi:10.7554/eLife.18904

Hattingh CJ, Ipser J, Tromp SA, Syal S, Lochner C, Brooks SJ, Stein DJ. 2013. Functional magnetic resonance imaging during emotion recognition in social anxiety disorder: an activation likelihood meta-analysis. Front Hum Neurosci 6: 347. doi:10.3389/fnhum.2012.00347

Hindy NC, Ng FY, Turk-Browne NB. 2016. Linking pattern completion in the hippocampus to predictive coding in visual cortex. Nat Neurosci 19: 665-667. doi:10.1038/nn.4284

Hitti FL, Siegelbaum SA. 2014. The hippocampal CA2 region is essential for social memory. Nature 508: 88-92. doi:10.1038/ nature 13028

Høydal ØA, Skytøen ER, Moser M, Moser EI. 2018. Objectvector coding in the medial entorhinal cortex. bioRxiv doi: $10.1101 / 286286$

Hsu DT, Sanford BJ, Meyers KK, Love TM, Hazlett KE, Walker SJ, Mickey BJ, Koeppe RA, Langenecker SA, Zubieta JK. 2015. It still hurts: altered endogenous opioid activity in the brain during social rejection and acceptance in major depressive disorder. Mol Psychiatry 20: 193-200. doi:10.1038/mp .2014 .185

Huber D, Veinante P, Stoop R. 2005. Vasopressin and oxytocin excite distinct neuronal populations in the central amygdala. Science 308: 245-248. doi:10.1126/science. 1105636

Insel TR, Fernald RD. 2004. How the brain processes social information: searching for the social brain. Annu Rev Neurosci 27: 697-722. doi:10.1146/annurev.neuro.27.070203.144148

Irle E, Ruhleder M, Lange C, Seidler-Brandler U, Salzer S, Dechent P, Weniger G, Leibing E, Leichsenring F. 2010. Reduced amygdalar and hippocampal size in adults with generalized social phobia. J Psychiatry Neurosci 35: 126-131. doi:10.1503/jpn.090041

Isovich E, Engelmann M, Landgraf R, Fuchs E. 2001. Social isolation after a single defeat reduces striatal dopamine transporter binding in rats. Eur J Neurosci 13: 1254-1256. doi:10 .1046/j.0953-816x.2001.01492.x

Javadi AH, Emo B, Howard LR, Zisch FE, Yu Y, Knight R, Pinelo Silva J, Spiers HJ. 2017. Hippocampal and prefrontal processing of network topology to simulate the future. Nat Commun 8: 14652 . doi:10.1038/ncomms 14652

Joiner TE, Timmons KA. 2002. Depression in its interpersonal context. In Handbook of depression (eds. Gotlib H, Hammen C), 2nd ed., pp. 322-339. Guilford Press, New York.

Julian JB, Keinath AT, Frazzetta G, Epstein RA. 2018. Human entorhinal cortex represents visual space using a boundaryanchored grid. Nat Neurosci 21: 191-194. doi:10.1038/ s41593-017-0049-1

Kaiser RH, Andrews-Hanna JR, Wager TD, Pizzagalli DA. 2015. Large-scale network dysfunction in major depressive disorder: meta-analysis of resting-state functional connectivity. JAMA Psychiatry 72: 603-611. doi:10.1001/jamapsychiatry.2015 .0071 
Kaplan R, Schuck NW, Doeller CF. 2017. The role of mental maps in decision-making. Trends Neurosci 40: 256-259. doi:10.1016/j.tins.2017.03.002

Kilts CD, Kelsey JE, Knight B, Ely TD, Bowman FDB, Gross RE, Selvig A, Gordon A, Newport DJ, Nemeroff CB. 2006. The neural correlates of social anxiety disorder and response to pharmacotherapy. Neuropsychopharmacology 31: 2243 2253. doi:10.1038/sj.npp.1301205

Knable MB, Barci BM, Webster MJ, Meador-Woodruff J, Torrey EF. 2004. Molecular abnormalities of the hippocampus in severe psychiatric illness: postmortem findings from the Stanley Neuropathology Consortium. Mol Psychiatry 9: 609-620. doi:10.1038/sj.mp.4001471

Kolomeets NS, Orlovskaya DD, Rachmanova VI, Uranova NA. 2005. Ultrastructural alterations in hippocampal mossy fiber synapses in schizophrenia: a postmortem morphometric study. Synapse 57: 47-55. doi:10.1002/syn.20153

Komorowski RW, Manns JR, Eichenbaum H. 2009. Robust conjunctive item-place coding by hippocampal neurons parallels learning what happens where. J Neurosci 29: 9918-9929. doi:10.1523/JNEUROSCI.1378-09.2009

Konradi C, Yang CK, Zimmerman EI, Lohmann KM, Gresch P, Pantazopoulos H, Berretta S, Heckers S. 2011. Hippocampal interneurons are abnormal in schizophrenia. Schizophr Res 131: 165-173. doi:10.1016/j.schres.2011.06.007

Krasny L, Williams BJ, Provencal S, Ozonoff S. 2003. Social skills interventions for the autism spectrum: essential ingredients and a model curriculum. Child Adolesc Psychiatr Clin N Am 12: 107-122. doi:10.1016/S1056-4993(02)00051-2

Kreiman G, Koch C, Fried I. 2000. Category-specific visual responses of single neurons in the human. Nat Neurosci 3: 946-953. doi:10.1038/78868

Kring AM, Caponigro JM. 2010. Emotion in schizophrenia: where feeling meets thinking. Curr Dir Psychol Sci 19: 255-259. doi:10.1177/0963721410377599

Kropff E, Carmichael JE, Moser MB, Moser EI. 2015. Speed cells in the medial entorhinal cortex. Nature 523: 419-424. doi:10.1038/nature14622

Kumaran D, Melo HL, Duzel E. 2012. The emergence and representation of knowledge about social and nonsocial hierarchies. Neuron 76: 653-666. doi:10.1016/j.neuron.2012.09.035

Kumaran D, Banino A, Blundell C, Hassabis D, Dayan P. 2016. Computations underlying social hierarchy learning: distinct neural mechanisms for updating and representing self-relevant information. Neuron 92: 1135-1147. doi:10.1016/j.neuron .2016 .10 .052

Kuroki N, Kubicki M, Nestor PG, Salisbury DF, Park HJ, Levitt JJ, Woolston S, Frumin M, Niznikiewicz M, Westin CF, et al. 2006. Fornix integrity and hippocampal volume in male schizophrenic patients. Biol Psychiatry 60: 22-31. doi:10.1016/j .biopsych.2005.09.021

Ladegaard N, Larsen ER, Videbech P, Lysaker PH. 2014. Higherorder social cognition in first-episode major depression. Psychiatry Res 216: 37-43. doi:10.1016/j.psychres.2013.12.010

Lawrence YA, Kemper TL, Bauman ML, Blatt GJ. 2010. Parvalbumin-, calbindin-, and calretinin-immunoreactive hippocampal interneuron density in autism. Acta Neurol Scand 121: 99-108. doi:10.1111/j.1600-0404.2009.01234.x

Lee RSC, Hermens DF, Porter MA, Redoblado-Hodge MA. 2012. A meta-analysis of cognitive deficits in first-episode major depressive disorder. J Affect Disord 140: 113-124. doi:10.1016/j.jad.2011.10.023

Leekam S. 2016. Social cognitive impairment and autism: what are we trying to explain? Philos Trans R Soc B Biol Sci 371: 20150082. doi: $10.1098 /$ rstb.2015.0082

Leitman DI, Laukka P, Juslin PN, Saccente E, Butler P, Javitt DC. 2010. Getting the cue: sensory contributions to auditory emotion recognition impairments in schizophrenia. Schizophr Bull 36: 545-556. doi:10.1093/schbul/sbn115

Liebowitz MR, Gorman JM, Fyer AJ, Klein DF. 1985. Social phobia. Review of a neglected anxiety disorder. Arch Gen Psychiatry 42: 729-736. doi:10.1001/archpsyc.1985.017903 00097013
Lin YT, Hsieh TY, Tsai TC, Chen CC, Huang C, Hsu K. 2017. Conditional deletion of hippocampal CA2/CA3a oxytocin receptors impairs the persistence of long-term social recognition memory in mice. J Neurosci 38: 1218-1231. doi:10.1523/ JNEUROSCI.1896-17.2017

Lodge DJ, Grace AA. 2011. Hippocampal dysregulation of dopamine system function and the pathophysiology of schizophrenia. Trends Pharmacol Sci 32: 507-513. doi:10.1016/j.tips .2011.05.001

LoParo D, Waldman ID. 2015. The oxytocin receptorgene (OXTR) is associated with autism spectrum disorder: a meta-analysis. Mol Psychiatry 20: 640-646. doi:10.1038/mp.2014.77

Lorberbaum JP, Kose S, Johnson MR, Arana GW, Sullivan LK, Hamner MB, Ballenger JC, Lydiard RB, Brodrick PS, Bohning DE, et al. 2004. Neural correlates of speech anticipatory anxiety in generalized social phobia. Neuroreport 15: 27012705.

MacDonald CJ, Lepage KQ, Eden UT, Eichenbaum H. 2011. Hippocampal "time cells" bridge the gap in memory for discontiguous events. Neuron 71: 737-749. doi:10.1016/j.neuron .2011.07.012

Machado CJ, Bachevalier J. 2006. The impact of selective amygdala, orbital frontal cortex, or hippocampal formation lesions on established social relationships in rhesus monkeys (Macaca mulatta). Behav Neurosci 120: 761-786. doi:10.1037/07357044.120.4.761

Machado-de-Sousa JP, Osório Fde L, Jackowski AP, Bressan RA, Chagas MHN, Torro-Alves N, DePaula ALD, Crippa JAS, Hallak JEC. 2014. Increased amygdalar and hippocampal volumes in young adults with social anxiety. PLoS One 9: e88523. doi:10.1371/journal.pone.0088523

MacQueen G, Frodl T. 2011. The hippocampus in major depression: evidence for the convergence of the bench and bedside in psychiatric research. Mol Psychiatry 16: 252-264. doi:10 $.1038 / \mathrm{mp} .2010 .80$

Meira T, Leroy F, Buss EW, Oliva A, Park J, Siegelbaum SA. 2018. A hippocampal circuit linking dorsal CA2 to ventral CA1 critical for social memory dynamics. Nat Commun 9: 4163. doi:10.1038/s41467-018-06501-w

Meyer-Lindenberg AS, Olsen RK, Kohn PD, Brown T, Egan MF, Weinberger DR, Berman KF. 2005. Regionally specific disturbance of dorsolateral prefrontal-hippocampal functional connectivity in schizophrenia. Arch Gen Psychiatry 32: 379386. doi:10.1001/archpsyc.62.4.379

Miller KJ, Botvinick MM, Brody CD. 2018. Dorsal hippocampus contributes to model-based planning. Nat Neurosci 20: 1269-1276. doi:10.1038/nn.4613

Mineur YS, Obayemi A, Wigestrand MB, Fote GM, Calarco CA, Li AM, Picciotto MR. 2013. Cholinergic signaling in the hippocampus regulates social stress resilience and anxiety- and depression-like behavior. Proc Natl Acad Sci 110: 3573-3578. doi:10.1073/pnas.1219731110

Minshew NJ, Goldstein G. 2001. The pattern of intact and impaired memory functions in autism. J Child Psychol Psychiatry 42: 1095-1101. doi:10.1111/1469-7610.00808

Montagrin A, Saiote C, Schiller D. 2018. The social hippocampus. Hippocampus 2: 672-679. doi:10.1002/hipo.22797

Okamoto K, Ikegaya Y. 2018. Recurrent connections between CA2 pyramidal cells. bioRxiv doi:10.1101/321513

O'Keefe J, Nadel L. 1978. The hippocampus as a cognitive map. Clarendon Press, Oxford.

Okuyama T, Kitamura T, Roy DS, Itohara S, Tonegawa S. 2016. Ventral CA1 neurons store social memory. Science 353: 15361541. doi:10.1126/science.aaf7003

Ólafsdóttir HF, Barry C, Saleem AB, Hassabis D, Spiers HJ. 2015. Hippocampal place cells construct reward related sequences through unexplored space. eLife 4: e06063. doi:10 .7554/eLife.06063

Omer DB, Maimon SR, Las L, Ulanovsky N. 2018. Social placecells in the bat hippocampus. Science 359: 218-224. doi:10 .1126/science.aao3474

Öngür D, Price JL. 2000. The organization of networks within the orbital and medial prefrontal cortex of rats, monkeys and 
humans. Cereb Cortex 10: 206-219. doi:10.1093/cercor/10.3 .206

Owen SF, Tuncdemir SN, Bader PL, Tirko NN, Fishell G, Tsien RW. 2013. Oxytocin enhances hippocampal spike transmission by modulating fast-spiking interneurons. Nature 500: 458-462. doi:10.1038/nature12330

Panenka WJ, Khorram B, Barr AM, Smith GN, Lang DJ, Kopala LC, Vandorpe RA, Honer WG. 2007. A longitudinal study on the effects of typical versus atypical antipsychotic drugs on hippocampal volume in schizophrenia. Schizophr Res 94: 288-292. doi:10.1016/j.schres.2007.05.002

Peñagarikano O. 2017. Oxytocin in animal models of autism spectrum disorder. Dev Neurobiol 77: 202-213. doi:10 $.1002 /$ dneu.22449

Penn DL, Sanna LJ, Roberts DL. 2008. Social cognition in schizophrenia: an overview. Schizophr Bull 34: 408-411. doi:10 .1093/schbul/sbn014

Perry D, Hendler T, Shamay-Tsoory SG. 2011. Projecting memories: the role of the hippocampus in emotional mentalizing. Neuroimage 54: 1669-1676. doi:10.1016/j.neuroimage.2010 .08 .057

Phillips ML, Senior C, David AS. 2000. Perception of threat in schizophrenics with persecutory delusions: an investigation using visual scan paths. Psychol Med 30: 157-167. doi:10 1017/S0033291799001397

Phillips ML, Robinson HA, Pozzo-Miller L. 2018. Ventral hippocampal projections to the medial prefrontal cortex regulate social memory. bioRxiv doi:10.1101/461533

Pinkham AE, Penn DL. 2006. Neurocognitive and social cognitive predictors of interpersonal skill in schizophrenia. Psychiatry Res 143: 167-178. doi:10.1016/j.psychres.2005.09.005

Piskorowski RA, Nasrallah K, Diamantopoulou A, Mukai J, Hassan SI, Siegelbaum SA, Gogos JA, Chevaleyre V. 2016. Age-dependent specific changes in area CA2 of the hippocampus and social memory deficit in a mouse model of the 22q11.2 deletion syndrome. Neuron 89: 163-176. doi:10 .1016/j.neuron.2015.11.036

Quian Quiroga R, Kraskov A, Koch C, Fried I. 2009. Explicit encoding of multimodal percepts by single neurons in the human brain. Curr Biol 19: 1308-1313. doi:10.1016/j.cub .2009 .06 .060

Raes F, Hermans D, Williams JMG, Demyttenaere K, Sabbe B, Pieters G, Eelen P. 2005. Reduced specificity of autobiographical memory: a mediator between rumination and ineffective social problem-solving in major depression? J Affect Disord 87: 331-335. doi:10.1016/j.jad.2005.05.004

Raymond GV, Bauman ML, Kemper TL. 1996. Hippocampus in autism: a Golgi analysis. Acta Neuropathol 91: 117-119. doi: $10.1007 / \mathrm{s} 004010050401$

Remington G, Foussias G, Fervaha G, Agid O, Takeuchi H, Lee J, Hahn M. 2016. Treating negative symptoms in schizophrenia: an update. Curr Treat Options Psychiatry 3: 133-150. doi:10.1007/s40501-016-0075-8

Rhebergen D, Beekman ATF, de Graaf R, Nolen WA, Spijker J, Hoogendijk WJ, Penninx BWJH. 2010. Trajectories of recovery of social and physical functioning in major depression, dysthymic disorder and double depression: a 3-year followup. J Affect Disord 124: 148-156. doi:10.1016/j.jad.2009.10 .029

Ross HE, Freeman SM, Spiegel LL, Ren X, Terwilliger EF, Young LJ. 2009. Variation in oxytocin receptor density in the nucleus accumbens has differential effects on affiliative behaviors in monogamous and polygamous voles. $J$ Neurosci 29: 1312-1318. doi:10.1523/JNEUROSCI.5039-08.2009

Sanders HI, Warrington EK. 1971. Memory for remote events in amnesic patients. Brain 94: 661-668. doi:10.1093/brain/94.4 .661

Sarel A, Finkelstein A, Las L, Ulanovsky N. 2017. Vectorial representation of spatial goals in the hippocampus of bats. Science 355: 176-180. doi:10.1126/science.aak9589

Sargolini F, Fyhn M, Hafting T, McNaughton BL, Witter MP, Moser MB. 2006. Conjunctive representation of position, di- rection, and velocity in entorhinal cortex. Science 312: 758 762. doi:10.1126/science. 1125572

Schacter DL, Addis DR, Hassabis D, Martin VC, Spreng RN, Szpunar KK. 2012. The future of memory: remembering, imagining, and the brain. Neuron 76: 677-694. doi:10.1016/ j.neuron.2012.11.001

Schafer M, Schiller D. 2018. Navigating social space. Neuron 100: 476-489. doi:10.1016/j.neuron.2018.10.006

Schilbach L, Eickhoff SB, Rotarska-Jagiela A, Fink GR, Vogeley K. 2008. Minds at rest? Social cognition as the default mode of cognizing and its putative relationship to the "default system" of the brain. Conscious Cogn 17: 457-467.

Schiller D, Eichenbaum H, Buffalo EA, Davachi L, Foster DJ, Leutgeb S, Ranganath C. 2015. Memory and space: towards an understanding of the cognitive map. J Neurosci 35: 13904 13911. doi:10.1523/JNEUROSCI.2618-15.2015

Schneider F, Weiss U, Kessler C, Müller-Gärtner HW, Posse S, Salloum JB, Grodd W, Himmelmann F, Gaebel W, Birbaumer N. 1999. Subcortical correlates of differential classical conditioning of aversive emotional reactions in social phobia. Biol Psychiatry 45: 863-871. doi:10.1016/S0006-3223(98) 00269-8

Schneier FR, Johnson J, Christopher D, Liebowitz MR, Weissman MM. 1992. Social phobia: comorbidity and morbidity in an epidemiologic sample. Arch Gen Psychiatry 49: 282-288. doi:10.1001/archpsyc.1992.01820040034004

Schumann CM, Hamstra J, Goodlin-Jones BL, Lotspeich LJ, Kwon H, Buonocore MH, Lammers CR, Reiss AL, Amaral DG. 2004. The amygdala is enlarged in children but not adolescents with autism: the hippocampus is enlarged at all ages. $J$ Neurosci 24: 6392-6401. doi:10.1523/JNEUROSCI.1297-04 .2004

Segrin C. 2000. Social skills deficits associated with depression. Clin Psychol Rev 20: 379-403. doi:10.1016/S0272-7358(98) 00104-4

Sigmundsson T, Suckling J, Maier M, Williams SCR, Bullmore ET, Greenwood KE, Fukuda R, Ron MA, Toone BK. 2001. Structural abnormalities in frontal, temporal, and limbic regions and interconnecting white matter tracts in schizophrenic patients with prominent negative symptoms. Am J Psychiatry 158: 234-243. doi:10.1176/appi.ajp.158.2.234

Silk JS, Lee KH, Kerestes R, Griffith JM, Dahl RE, Ladouceur CD. 2017. "Loser" or "popular"? Neural response to social status words in adolescents with major depressive disorder. Dev Cogn Neurosci 28: 1-11. doi:10.1016/j.den.2017.09.005

Singer AC, Frank LM. 2009. Rewarded outcomes enhance reactivation of experience in the hippocampus. Neuron 64: 910 921. doi:10.1016/j.neuron.2009.11.016

Smeltzer MD, Curtis JT, Aragona BJ, Wang Z. 2006. Dopamine, oxytocin, and vasopressin receptor binding in the medial prefrontal cortex of monogamous and promiscuous voles. Neurosci Lett 394: 146-151. doi:10.1016/j.neulet.2005.10.019

Smith AS, Williams Avram SK, Cymerblit-Sabba A, Song J, Young WS. 2016. Targeted activation of the hippocampal CA2 area strongly enhances social memory. Mol Psychiatry 21: 1137-1144. doi:10.1038/mp.2015.189

Solstad T, Boccara CN, Kropff E, Moser M-B, Moser EI. 2008. Representation of geometric borders in the entorhinal cortex. Science 322: 1865-1868. doi:10.1126/science.1166466

Sripada CS, Angstadt M, Banks S, Nathan PJ, Liberzon I, Phan KL. 2009. Functional neuroimaging of mentalizing during the trust game in social anxiety disorder. Neuroreport 20: 984 989. doi:10.1097/WNR.0b013e32832d0a67

Stachenfeld KL, Botvinick MM, Gershman SJ. 2017. The hippocampus as a predictive map. Nat Neurosci 20: 1643-1653. doi: $10.1038 / \mathrm{nn} .4650$

Stein MB, Stein DJ. 2008. Social anxiety disorder. Lancet 371: 1115-1125. doi:10.1016/S0140-6736(08)60488-2

Stein MB, Goldin PR, Sareen J, Zorrilla LTE, Brown GG. 2002. Increased amygdala activation to angry and contemptuous faces in generalized social phobia. Arch Gen Psychiatry 59: 1027. doi:10.1001/archpsyc.59.11.1027 
Stiller J, Dunbar RIM. 2007. Perspective-taking and memory capacity predict social network size. Soc Networks 29: 93104. doi:10.1016/j.socnet.2006.04.001

Stockmeier CA, Mahajan GJ, Konick LC, Overholser JC, Jurjus GJ, Meltzer HY, Uylings HBM, Friedman L, Rajkowska G. 2004. Cellular changes in the postmortem hippocampus in major depression. Biol Psychiatry 56: 640-650. doi:10 $.1016 /$ j.biopsych.2004.08.022

Syal S, Hattingh CJ, Fouché JP, Spottiswoode B, Carey PD, Lochner C, Stein DJ. 2012. Grey matter abnormalities in social anxiety disorder: a pilot study. Metab Brain Dis 27: 299-309. doi:10.1007/s11011-012-9299-5

Szanto K, Dombrovski AY, Sahakian BJ, Mulsant BH, Houck PR, Reynolds CF III Clark L. 2012. Social emotion recognition, social functioning, and attempted suicide in late-life depression. Am J Geriatr Psychiatry 20: 257-265. doi:10 $.1097 /$ JGP.0b013e31820eea0c

Tamminga CA, Stan AD, Wagner AD. 2010. The hippocampal formation in schizophrenia. Am J Psychiatry 167: 1178-1193. doi:10.1176/appi.ajp.2010.09081187

Tavares RM, Mendelsohn A, Grossman Y, Williams CH, Shapiro M, Trope Y, Schiller D. 2015. A map for social navigation in the human brain. Neuron 87: 231-243. doi:10.1016/j.neuron .2015.06.011

Taylor SF, Kang J, Brege IS, Tso IF, Hosanagar A, Johnson TD. 2012. Meta-analysis of functional neuroimaging studies of emotion perception and experience in schizophrenia. Biol Psychiatry 71: 136-145. doi:10.1016/j.biopsych.2011.09.007

Teki S, Kumar S, von Kriegstein K, Stewart L, Lyness CR, Moore BCJ, Capleton B, Griffiths TD. 2012. Navigating the auditory scene: an expert role for the hippocampus. $J$ Neurosci 32: 12251-12257. doi:10.1523/JNEUROSCI $.0082-12.2012$

Thara R, Srinivasan TN. 1997. Outcome of marriage in schizophrenia. Soc Psychiatry Psychiatr Epidemiol 32: 416-420.

Tillfors M, Furmark T, Marteinsdottir I, Fredrikson M. 2002. Cerebral blood flow during anticipation of public speaking in social phobia: a PET study. Biol Psychiatry 52: 11131119. doi:10.1016/S0006-3223(02)01396-3

Tirko NN, Eyring KW, Carcea I, Mitre M, Chao MV, Froemke RC, Tsien RW. 2018. Oxytocin transforms firing mode of CA2 hippocampal neurons. Neuron 100: 593-608. doi:10.1016/j .neuron.2018.09.008

Todorov A, Gobbini MI, Evans KK, Haxby JV. 2007. Spontaneous retrieval of affective person knowledge in face perception. Neuropsychologia 45: 163-173. doi:10.1016/j.neuropsy chologia.2006.04.018

Todorov A, Said CP, Engell AD, Oosterhof NN. 2008. Understanding evaluation of faces on social dimensions. Trends Cogn Sci 12: 455-460. doi:10.1016/j.tics.2008.10.001

Tolman EC. 1948. Cognitive maps in rats and men. Psychol Rev 55: 189-208. doi:10.1037/h0061626
Tovote P, Fadok JP, Lüthi A. 2015. Neuronal circuits for fear and anxiety. Nat Rev Neurosci 16: 317-331. doi:10.1038/nrn3945

Trinkler I, King JA, Doeller CF, Rugg MD, Burgess N. 2009. Neural bases of autobiographical support for episodic recollection of faces. Hippocampus 19: 718-730. doi:10.1002/hipo .20556

Uhlhaas PJ, Phillips WA, Schenkel LS, Silverstein SM. 2006. Theory of mind and perceptual context-processing in schizophrenia. Cogn Neuropsychiatry 11: 416-436. doi:10.1080/ 13546800444000272

Walum H, Young LJ. 2018. The neural mechanisms and circuitry of the pair bond. Nat Rev Neurosci 19: 643-654. doi:10.1038/ s41583-018-0072-6

Wang L, Mamah D, Harms MP, Karnik M, Price JL, Gado MH, Thompson PA, Barch DM, Miller MI, Csernansky JG. 2008. Progressive deformation of deep brain nuclei and hippocampal-amygdala formation in schizophrenia. Biol Psychiatry 64: 1060-1068. doi:10.1016/j.biopsych.2008.08.007

Wible CG, Anderson J, Shenton ME, Kricun A, Hirayasu Y, Tanaka S, Levitt JJ, O'Donnell BF, Kikinis R, Jolesz FA, et al. 2001. Prefrontal cortex, negative symptoms, and schizophrenia: an MRI study. Psychiatry Res 108: 65-78. doi:10 .1016/S0925-4927(01)00109-3

Williams JM, Ellis NC, Tyers C, Healy H, Rose G, MacLeod AK. 1996. The specificity of autobiographical memory and imageability of the future. Mem Cognit 24: 116-25. doi:10.3758/ BF03197278

Williams DL, Goldstein G, Minshew NJ. 2005. Impaired memory for faces and social scenes in autism: clinical implications of memory dysfunction. Arch Clin Neuropsychol 20: 1-15. doi:10.1016/j.acn.2002.08.001

Wolkenstein L, Schönenberg M, Schirm E, Hautzinger M. 2011. I can see what you feel, but I can't deal with it: impaired theory of mind in depression. J Affect Disord 132: 104-111. doi:10 $.1016 /$ j.jad.2011.02.010

Wood ER, Dudchenko PA, Robitsek RJ, Eichenbaum H. 2000. Hippocampal neurons encode information about different types of memory episodes occurring in the same location. Neuron 27: 623-633. doi:10.1016/S0896-6273(00)00071-4

Yassa MA, Stark CEL. 2011. Pattern separation in the hippocampus. Trends Neurosci 34: 515-525. doi:10.1016/j.tins.2011.06 .006

Zhou Y, Shu N, Liu Y, Song M, Hao Y, Liu H, Yu C, Liu Z, Jiang T. 2008. Altered resting-state functional connectivity and anatomical connectivity of hippocampus in schizophrenia. Schizophr Res 100: 120-132. doi:10.1016/j.schres.2007.11 .039

Zhu X, Wang X, Xiao J, Liao J, Zhong M, Wang W, Yao S. 2012. Evidence of a dissociation pattern in resting-state default mode network connectivity in first-episode, treatment-naive major depression patients. Biol Psychiatry 71: 611-617. doi:10 $.1016 /$ j.biopsych.2011.10.035 


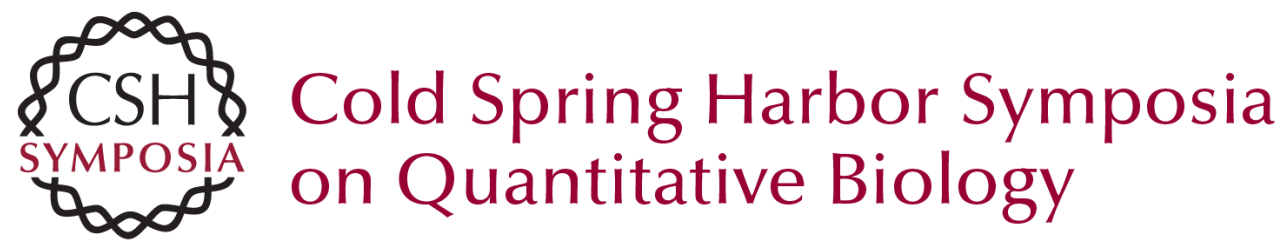

\section{The Hippocampus and Social Impairment in Psychiatric Disorders}

Matthew Schafer and Daniela Schiller

Cold Spring Harb Symp Quant Biol 2018 83: 105-118 originally published online February 20, 2019

Access the most recent version at doi:10.1101/sqb.2018.83.037614

References This article cites 176 articles, 23 of which can be accessed free at: http://symposium.cshlp.org/content/83/105.full.html\#ref-list-1

Creative This article is distributed under the terms of the

Commons http://creativecommons.org/licenses/by-nc/4.0/, which permits reuse and

License redistribution, except for commercial purposes, provided that the original author and source are credited.

Email Alerting Receive free email alerts when new articles cite this article - sign up in Service the box at the top right corner of the article or click here. 